\title{
The Challenge and Need of Defining Axial Psoriatic Arthritis
}



Psoriatic arthritis (PsA) is a complex rheumatic disease in terms of clinical evaluation; joint polymorphism and the presence of dactylitis, enthesitis, and skin and nail involvement contribute little to clarifying the best definition for clinical evaluation ${ }^{1}$.

Although the CASPAR criteria were developed with the aim of achieving wide consensus on the classification of PsA, several points within these criteria were left unresolved $^{2}$. By definition, according to these criteria, a patient can be classified as having PsA if there is an inflammatory musculoskeletal disease, including peripheral arthritis, spinal disease, or enthesitis, together with other characteristic features of PsA.

Spinal involvement has long been recognized in PsA (axPsA). Since early descriptions recognizing inflammatory back disease as one of the patterns of joint involvement in PsA, several reports have dealt with the issue of PsA spinal involvement ${ }^{3}$. The prevalence of involvement varies due to the lack of an accepted definition of spinal involvement in axPsA; according to several reports, spinal involvement in patients with PsA ranges from $25 \%$ to $70 \%$ of cases ${ }^{4-6}$.

Despite these limitations, recent work has demonstrated that, if the spine is involved, several measurements borrowed from ankylosing spondylitis (AS) can be used to clinically assess patients with axPsA ${ }^{7,8}$. In this issue of The Journal Chandran and colleagues add another important piece of the puzzle regarding the definition of axPsA ${ }^{9}$.

Chandran and colleagues update information on the Toronto PsA cohort ${ }^{4}$. The authors show that a radiological classification of axial involvement regardless of clinical symptoms may suffice for defining spinal disease in PsA. There is symptom improvement over time (which may or may not be related to medication - the problem of painless involvement along with radiological deterioration in PsA is not yet resolved) that parallels structural progression; this translates into deterioration of spinal mobility measures such as lateral lumbar flexion and cervical mobility, resulting in restriction in physical function. Thus their study rais- es many important and interesting questions that need to be addressed in the near future.

There is much controversy about whether axPsA is a disease on its own or is a form of AS with psoriasis. Although not specifically addressed in the current report by Chandran and colleagues, many patients studied clearly met the modified New York criteria for AS; however, they probably met the CASPAR criteria as well. This point underscores the need to define what spinal disease means in PsA. Regardless of the similarities that axPsA may have with AS, there are also important differences, such as the peripheral component, which is not seen as frequently in AS. On the other hand, HLA-B27 strongly associated to AS does not seem to play the same role in the development of axPsA; the prevalence of HLA-B27 in axPsA is rather low compared to $\mathrm{AS}^{10-12}$.

Another important issue that may clarify the difference between axPsA and AS is what can be called "painless disease"; "asymptomatic" joint involvement in PsA patients seems not to be limited to the axial or the peripheral joints.

In Chandran's patient, symptoms improved over time; and while in this case it cannot be ruled out that improvement was due to medication, similar data have already been seen in axial involvement ${ }^{11}$ and in peripheral arthritis (early and long-standing PsA) $)^{13,14}$; moreover, some psoriatic patients showed erosive hand disease without ever having a joint complaint (unpublished observation). These data lead clinicians to an unresolved clinical problem: although asymptomatic, the spinal disease progresses (structurally speaking), as seen in the deterioration of cervical mobility and lateral spinal flexion.

Whereas in AS, magnetic resonance imaging (MRI) has become an important tool for evaluation of inflammation and response to therapy in both the sacroiliac joints and the spine $^{15,16}$, data specifically evaluating axPsA are sparse ${ }^{12}$. Therefore we do not know whether asymptomatic disease translates into non-bone inflammation as evaluated by MRI, or, on the contrary, there is asymptomatic disease with bone

See Axial PsA: Update on a longterm prospective, page 2744

Personal non-commercial use only. The Journal of Rheumatology Copyright @ $\subset$ 2009. All rights reserved. 
inflammation on MRI. If the latter were the case, clinicians would need to know what to do from a clinical point of view.

As mentioned above, as a result of structural damage (disease progression) patients with axPsA in the long term have decreased spinal mobility. Due to the ever changing field of spondyloarthritis, spinal mobility in Chandran's report was not evaluated with current measures to assess spinal disease; however, their results confirm work already done in assessing axPsA with current spinal measurements $^{7,8}$. In view of current knowledge, patients with PsA who have spinal disease should be followed regularly at clinics using these standard measurements.

Biologic therapy has greatly advanced the treatment of several inflammatory rheumatic diseases including PsA. Although biologics work well in $\mathrm{PsA}^{17}$, the lack of a definition of axPsA and a lack of tools to evaluate disease activity have hampered research into their usefulness in axPsA. Currently, it is assumed that biologic therapy works ${ }^{18}$, although no solid evidence has been produced. Recent work evaluating the Bath Ankylosing Spondylitis Disease Activity Index as a measure of disease activity in axPsA has not shown promising results utilizing this tool ${ }^{19,20}$. Due to the complexity of joint involvement in PsA, current data point to a need to develop a composite index that will permit us to evaluate peripheral and spinal disease.

Future studies with imaging techniques such as MRI, as well as deeper research into genetics and biomarkers, will help to better define spinal involvement in early and longstanding PsA. In the meantime, in light of current knowledge, radiologic classification may be a good starting point.

Clinicians should be aware that, in evaluating PsA, the spine counts: regardless of peripheral joint involvement, patients with spinal involvement should be classified and spinal measurement implemented in daily clinical care in patients with axPsA.

\section{JOSÉ LUIS FERNÁNDEZ-SUEIRO, MD,} Rheumatology Division,

Hospital Universitario Juan Canalejo,

La Coruña, Spain

Address correspondence to Dr. J.L. Fernández-Sueiro, Rheumatology Division, Hospital Universitario Juan Canalejo, C/ Xubias, 84, 15006, La Coruña, Galicia, Spain.E-mail: L.sueiro@canalejo.org

\section{REFERENCES}

1. Gladman D, Mease P, Healy P, Helliwell P, Fitzgerald O, Cauli A, et al. Outcome measures in psoriatic arthritis. J Rheumatol 2007;34:1159-66.

2. Taylor W, Gladman D, Helliwell P, Marchesoni A, Mease P, Mielants $\mathrm{H}$ and the CASPAR study group. Classification criteria for psoriatic arthritis: development of new criteria from a large international study. Arthritis Rheum 2006;54:2665-73.
3. Wright V. Psoriasis and arthritis. Ann Rheum Dis 1956;15:348-53.

4. Hanly J, Russell M, Gladman D. Psoriatic spondyloarthropathy: a long term prospective study. Ann Rheum Dis 1988;47:386-93.

5. Lambert J, Wright V. Psoriatic spondylitis: a clinical and radiological description of the spine in psoriatic arthritis. Q J Med 1977;46:411-25.

6. Battistone M, Manaster B, Reda D, Clegg D. The prevalence of sacroiliitis in psoriatic arthritis: new perspectives from a large multicenter cohort. A Department of Veterans Affair Cooperative Study. Skeletal Radiol 1999;28:196-201.

7. Gladman DD, Inman RD, Cook RJ, van der Heijde D, Landewé RB, Braun J, et al. International spondyloarthritis interobserver reliability exercise - the INSPIRE study: I. Assessment of spinal measures. J Rheumatol 2007;34:1733-9.

8. Fernandez-Sueiro JL, Willisch A, Pértega Díaz S, Pinto Tasende JA, Fernández C, Galdo F, et al. Evaluation of ankylosing spondylitis spinal mobility measurements in the assessment of spinal involvement in psoriatic arthritis. Arthritis Rheum 2009;61:386-92.

9. Chandran V, Barrett J, Schentag C, Farewell V, Gladman D. Axial psoriatic arthritis: update on a longterm prospective study. J Rheumatol 2009;36:2744-50.

10. Gladman D, Brubacher B, Buskila D, Langevitz P, Farewell V. Psoriatic spondyloarthropathy in men and women: a clinical, radiographic and HLA study. Clin Invest Med 1992;15:371-5.

11. Queiro R, Belzunegui J, Gonzalez C, De Dios J, Sarasqueta C, Torre $\mathrm{J}$, et al. Clinically asymptomatic axial disease in psoriatic spondyloarthropathy. A retrospective study. Clin Rheumatol 2002;21:10-3.

12. Williamson L, Dockerty J, Dalbeth N, McNally E, Ostlere S, Wordsworth B. Clinical assessment of sacroiliitis and HLA-B27 are poor predictors of sacroiliitis diagnosed by magnetic resonance imaging in psoriatic arthritis. Rheumatology 2004;43:85-8.

13. Scarpa R, Cuoculo A, Peluso R, Atteno M, Gissoni P, Lervolino S, et al. Early psoriatic arthritis: the clinical spectrum. J Rheumatol 2008;35:137-41.

14. Palazzi C, D'Agostino L, D'Amico E, Pennese E, Petricca A. Asymptomatic erosive peripheral arthritis: a frequent finding in Italian patients. Rheumatology 2003;42:909-11.

15. Braun J, Bollow M, Eggens U, König H, Distler A, Sieper J. Use of dynamic magnetic resonance imaging with fast imaging in the detection of early and advanced sacroiliitis in spondyloarthropathy patients. Arthritis Rheum 1994;37:1039-45.

16. Baralaikos X, Davis J, Tsuji W, Braun J. Magnetic resonance imaging examinations of the spine in patients with ankylosing spondylitis before and after therapy with the tumor necrosis factor alpha receptor fusion protein etanercept. Arthritis Rheum 2005;52:1216-23.

17. Mease P. Biological agents in psoriatic arthritis. In: Ritchlin C, Fitzgerald O, editors. Psoriatic and reactive arthritis. Philadelphia: Mosby Elsevier; 2007:102-13.

18. Nash P. Therapies for axial disease in psoriatic arthritis. A systematic review. J Rheumatol 2006;33:1431-4.

19. Taylor WJ, Harrison AA. Could the Bath Ankylosing Spondylitis Disease Activity Index (BASDAI) be a valid measure of disease activity in patients with psoriatic arthritis? Arthritis Rheum 2004;51:311-5.

20. Fernandez-Sueiro JL, Willisch A, Pértega-Díaz S, Pinto Tasende JA, Fernández-López JC, Oreiro Villar N, et al. Validity of the BASDAI for the evaluation of disease activity in axial psoriatic arthritis. Arthritis Rheum; (in press).

J Rheumatol 2009;36:2633-4; doi:10.3899/jrheum.091023 